\title{
Customer-Centric Knowledge Creation For Customer Relationship Management
}

Phocharapol Srisamran, Mahidol University, Thailand

Vichita Vathanophas Ractham, Mahidol University, Thailand

\begin{abstract}
As the pace of today's world increases with advances in technology and globalization, the heat of rivalry and competition in the business world is also rising. It is a wake-up call for many firms that they can no longer just convince customers to buy whatever they sell. They have to understand their customers. Customer Relationship Management (CRM) can assist firms to "know your customer" and "construct good relationships with customers." In order to know your customer and construct a good relationship, customer knowledge must be acquired and managed. However, this is no easy task since customer knowledge can be subjective and difficult to extract or manage. An approach is needed to acquire and manage customer knowledge. Knowledge management, including knowledge creation, can assist in terms of acquiring and managing customer knowledge. Knowledge management not only improves understanding of the customer, but also improves business process performance by enabling response to customer needs in a timely manner with better quality of service. Customer-Centric Knowledge Creation is the process for the creation of knowledge based on customer knowledge within the CRM contexts which are enterprise-wide, customer-centric, technology-driven, and cross-functional. The aims of this process are to assist organizations to gain more understanding of the customer, embedding customer knowledge into organization knowledge, and creating a customer-focused mindset in organizational members. In other words, it is to sustainably create knowledge focusing on customer knowledge in an organization.
\end{abstract}

Keywords: Knowledge Management; Knowledge Creation; Customer Relationship Management; Customer Knowledge

\section{INTRODUCTION}

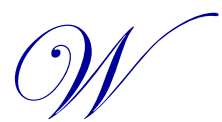

hat if you were living in a world where you could sell whatever you produced? Wouldn't that be a dream world? But wake up to reality. We cannot deny that we are living in a world that is packed with people and products. Competition, challenge and rivalry are found everywhere. The competition is ever fiercer. Businesses are realizing that customer power is increasing and they have to uncover the customers' motivations and needs when buying products (Bose, 2002). Businesses have realized that "they have to make what people want instead of trying to convince them to buy whatever they have to sell" (Bose, 2002, p. 90). In other words, they have to get to "know their customers."

Customer Relationship Management or CRM can assist firms to know their customers better and develop good relationships with them. However, in order to achieve these two objectives, customer knowledge plays a significant role. The question now is "How" right? Other questions you might have include: What is the importance of customer knowledge in CRM? What is the relationship between customer knowledge, CRM and knowledge management? Why should knowledge creation be implemented in CRM? These topics will be explained in the "Customer Relationship Management \& Knowledge Management" section.

This paper is structured into three main sections. First, we will take a look at the concept and definition of Customer Relationship Management. Next, the definitions of knowledge, knowledge management, and knowledge creation concepts are reviewed. Then, we will look at the relationship between CRM, knowledge management, and 
customer knowledge. Finally, the conceptual framework of Customer-Centric Knowledge Creation for CRM is proposed and analyzed. This paper concludes with a summary and an outlook for further research opportunities.

\section{CUSTOMER RELATIONSHIP MANAGEMENT}

People have heard the term "Customer Relationship Management" or "CRM" for several years. However, what do they really understand about this concept? Many people perceive "Customer Relationship Management" as a technology or a system (Payne \& Frow, 2005; Chen \& Popovich, 2003; Prasonsukarn, 2009). Some perceive it as marketing tools (e.g. direct mail, loyalty card, etc.) while some perceive it as the help desk or even call center (Payne \& Frow, 2005). In fact, CRM is more than just technology (Chen \& Popovich, 2003; Bose, 2002; Paas \& Kuijlen, 2001; Payne \& Frow, 2005; Prasonsukarn, 2009; Parvatiyar \& Sheth, 2001). It requires the cooperation and commitment from people within an organization in order to successfully implement CRM (Bose, 2002; Chen \& Popovich, 2003; Prasongsukarn, 2009). Therefore, defining CRM as a technology solution for certain departments (e.g. marketing and customer service) does not utilize this concept efficiently. Many authors have given different definitions to CRM. Parvatiyar \& Sheth define it as "Customer Relationship Management is a comprehensive strategy and process of acquiring, retaining, and partnering with selective customers to create superior value for the company and the customer. It involves the integration of marketing, sales, customer service, and the supply-chain functions of the organization to achieve greater efficiencies and effectiveness in delivering customer value." (2001, p. 5). Bose refers to CRM as "CRM is an integration of technologies and business processes used to satisfy the needs of customer during any given interaction." (2002, p. 89). Payne and Frow suggest that "CRM is a strategic approach that is concerned with creating improved shareholder value through the development of appropriate relationships with key customers and customer segments." (2005, p. 168). While many authors refer to CRM as a strategic approach or integration between business process and technology, there is some evidence that reveals the importance of executives' and employees' readiness for CRM (Chen \& Popovich, 2003; Bentum \& Stone, 2005; Meyer \& Goes, 1988). Chen and Popovich, (2003) introduce another dimension of CRM, which is people, by identifying the key dimensions as "CRM is a combination of people, process and technology that seeks to understand a company's customers" (2003, p. 672). Chen and Popovich, (2003) develop a CRM implementation model based on this concept. The result is a CRM implementation model that combines the three key dimensions of CRM which are people, process and technology within the context of an enterprise-wide, customer-centric, technology-driven, cross-functional organization as shown in Figure 1.

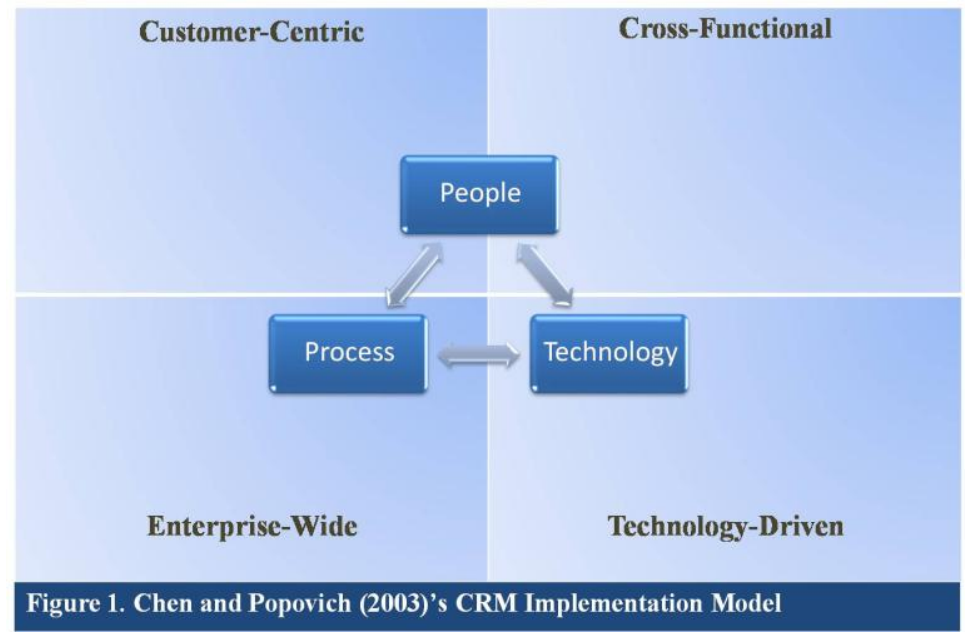

According to Chen and Popovich (2003)'s CRM implementation model, the key dimensions of CRM are people, process and technology. In order to implement CRM, these dimensions must be focused and developed in the context of an enterprise-wide, customer-centric, technology-driven, cross-functional organization. People refer to members in an organization including executives and employees. Members in an organization must have commitment in order to implement CRM. A customer-oriented mindset in members in an organization is crucial for implementing CRM. Business process re-engineering can take place in an organization in order to make the current 
business processes become more customer-oriented. The technology component is the enabler and driver for facilitating the change in business process and improving organization performance. Therefore, the selected software and technology should be necessary and relevant rather than complex and sophisticated (Paas \& Kuijlen, 2001).

of:

The CRM contexts that are mentioned in Chen and Popovich (2003)'s CRM implementation model consist

- Customer-Centric: Since CRM is focusing on customers, customer-centric context means that the whole organization focus must be on customers. Organizational members must have a customer-focused mindset. This is not meant to apply only to organizational members, but also to the process. The processes in an organization must be aligned with customer-focused mindset as well (Chen \& Popovich, 2003; Prasonsukarn, 2009).

- Cross-Functional: CRM cannot be applied in a single department. It requires collaboration and commitment from organizational members in every department in an organization. This is because CRM implementation is not focused only on one department, it is for the whole organization. When implementing CRM, it is necessary to conduct process re-engineering in order for it to be aligned with the customer-focused mindset. Change must occur. Therefore, CRM implementation requires every organizational member to participate and collaborate in this change (Chen \& Popovich, 2003; Prasonsukarn, 2009).

- Technology-Driven: Technology is considered as an enabler or driver in CRM. Technologies like data mining or data warehouse or CRM software allow the organization to obtain, manage, process, and interpret customer information more conveniently and efficiently. However, the organization must analyze and consider whether the existing technology in the organization is efficient enough to respond to the change aligned with customer-focused mindset change (Chen \& Popovich, 2003; Prasonsukarn, 2009).

- $\quad$ Enterprise-Wide: Since the implementation of CRM should not be limited to a particular department, it should be implemented across the entire company. The customer-focused mindset also becomes a part of the organization. The vision and goals of the organization should also be aligned with the customer-focused mindset (Chen \& Popovich, 2003; Prasonsukarn, 2009).

In line with these definitions of CRM, the author defines CRM as "the strategic process focusing on getting to know your customers better and using customer knowledge in order to construct and maintain relationships with them. CRM is the integration between people, process and technology in the context of enterprise-wide, customercentric, technology-driven, and cross-functional organization."

\section{KNOWLEDGE IN ORGANIZATION: DEFINITION \& PERSPECTIVE}

What is knowledge? How is it different from information? These questions are likely to occur to many people, since many people are unable to distinguish the dissimilarity between these two concepts. Nonaka and Takeuchi (1995) propose that while the information is a flow of message, knowledge is created by the combination of information, individual's belief and commitment of its possessor. Davenport and Prusak (1998) also mention that knowledge is the combination between contextual information and an individual's experience, values and insight. Alavi and Leidner (2001, p. 109) provide an interesting perspective in distinguishing between knowledge and information. The key for distinguishing between knowledge and information is that "knowledge is information possessed in the mind of individuals: it is personalized information (which may or may not be new, unique, useful or accurate) related to facts, procedures, concepts, interpretations, ideas, observations, and judgments."

For knowledge in an organization, Nonaka $(1994,1998)$ classifies the knowledge in an organization into two dimensions: tacit and explicit. The tacit dimension of knowledge or tacit knowledge is personal, difficult to formalize and communicate to other individuals including both technical side (e.g. personal skill, know-how, etc.) and cognitive side (e.g. personal values, beliefs, ideals, etc.). The explicit dimension of knowledge or explicit knowledge is more formal and convenient to communicate to other individuals since it is articulated and codified into words and numbers in the form of specifications, manuals, formulae, etc. Since these two kinds of knowledge are present in an organization, the interaction between these two kinds of knowledge can occur in an organization as well. Whether it is the interaction between tacit knowledge and tacit knowledge, explicit knowledge and explicit 
knowledge, or tacit knowledge and explicit knowledge, these interactions lead to the process of knowledge creation which is described in the next section.

\section{KNOWLEDGE MANAGEMENT}

Alavi and Leidner (2001) propose that knowledge management consists of four basic processes which are: 1) knowledge creation, 2) knowledge storage/retrieval, 3) knowledge transfer, and 4) knowledge application.

1. Knowledge Creation: A process which involves the interactions between tacit and explicit knowledge in spiral movement that leads to the creation of knowledge (Nonaka, 1994, 1998). The interactions between these two types of knowledge that lead to knowledge creation are represented in Nonaka (1998)'s SECI model. The SECI model comprises of four fundamental stages which are socialization, externalization, combination, and internalization.

2. Knowledge Storage/Retrieval: Organizational memory refers to storage and retrieval of organizational knowledge (Stein \& Zwass, 1995; Walsh \& Ungson, 1991). Knowledge that is stored in organizational memory can be in many forms (i.e. written document, e-database, etc.). The forms of stored knowledge can be classified as follows:

a) Semantic memory: It is the knowledge which appears in general explicit knowledge (e.g. archives of annual reports).

b) Episodic memory: It is the knowledge which appears in specific situations and periods (e.g. specific decision making situations).

3. Knowledge Transfer: Knowledge transfer process involves two actors, the knowledge provider and the knowledge receiver. Conceptual knowledge transfer framework (Gupta \& Govindarajan, 2000) consists of five elements described as follows:

a) Acknowledgement of the value of knowledge from the knowledge provider

b) Willingness to share the knowledge of the knowledge provider

c) Knowledge transfer channel must exist. The knowledge transfer channel can be categorized into two categories: Informal (i.e. unscheduled meeting, informal seminar, conversation during coffee break, etc.) and Formal (i.e. training session, plant tour, etc.)

d) Willingness to receive the knowledge from the knowledge provider

e) Ability to acquire and use the knowledge

4. Knowledge Application: There are three primary mechanisms for knowledge integration in order to create organizational competence (Grant, 1996):

a) Derivatives: Set of standards or procedure to convert tacit knowledge from specialist into explicit knowledge that is easier and more understandable for non-specialist.

b) Organizational routine: Individuals can integrate their expert knowledge without the need to communicate to others by using developed coordination or interaction protocols.

c) Creation of self-contained task teams: Individuals can form teams with specialized knowledge for problem solving.

\section{KNOWLEDGE CREATION}

Knowledge creation is one of the four basic knowledge processes which are: 1) knowledge creation, 2) knowledge storage/retrieval 3) knowledge transfer, and 4) knowledge application (Alavi \& Leidner, 2001). For the knowledge creation process, Nonaka $(1994,1998)$ refers to knowledge creation as a process which involves the interactions between tacit and explicit knowledge. The interaction between tacit and explicit knowledge also leads to the conversion of knowledge between these two categories of knowledge. Tacit knowledge can be converted to explicit knowledge and vice versa. Tacit knowledge can also be converted into new tacit knowledge. This case can also apply to the conversion between explicit knowledge and explicit knowledge. These movements of interaction between tacit and explicit knowledge are in the spiral movements flowing from one stage to another. Nonaka (1994, 1998) referred to this process as SECI model. SECI model is widely accepted in the knowledge management field and is very practical in terms of identifying how knowledge can be created. This model has been used in many cases. For instance, the application of SECI model in a multi-organizational project (Rice \& Rice, 2005), the application of SECI model in Russian companies (Andreeva \& Ikhilchik, 2011). In SECI model, there are four 
stages in which tacit knowledge and explicit knowledge interact with each other to create new knowledge. Figure 2 illustrates how tacit knowledge and explicit knowledge interact in SECI model.

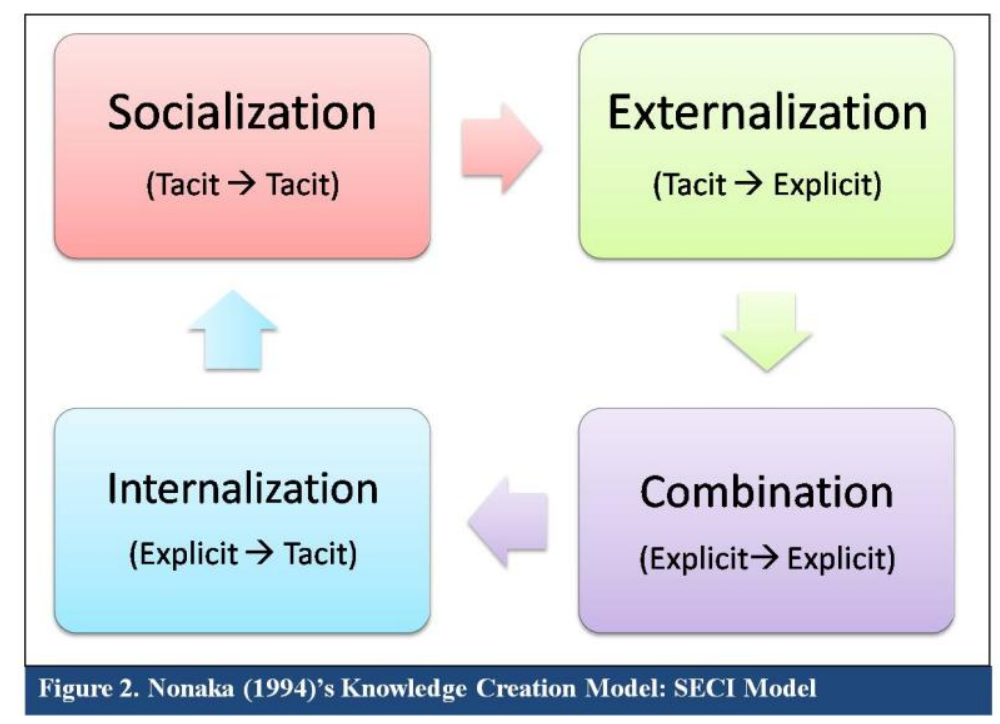

- $\quad$ Socialization (Tacit knowledge $\rightarrow$ Tacit knowledge): Socialization refers to the creation of new knowledge by exchanging individual's tacit knowledge with another individual's tacit knowledge through mutual activities (Nonaka, 1994; Alavi, 2001). Mutual activities refer to activities where individuals are spending time together in the same environment rather than following verbal or documented instructions. In this stage, there are two significant aspects involved in converting tacit knowledge into new tacit knowledge. The first aspect is physical closeness. Tacit knowledge can be acquired through direct interaction between individuals. The second aspect is tacit knowledge dissemination. Socialization is concerned with the exchanging of tacit knowledge. Therefore, how individuals disseminate their own tacit knowledge is important since the process of transferring one individual's idea to another is not trouble-free.

- $\quad$ Externalization (Tacit knowledge $\rightarrow$ Explicit knowledge): Externalization refers to creation of new knowledge by expressing individual's tacit knowledge and translating it into new comprehensive explicit knowledge that can be understood by others (Nonaka, 1994; Alavi, 2001). In this stage, there are two significant processes involved with converting tacit knowledge into explicit knowledge. The first process is articulating an individual's tacit knowledge. This process involves individuals having to convert their tacit knowledge into explicit knowledge. In other words, it is how individuals express their ideas, thoughts, knowledge into words, documents, graphs, etc. The second process is translating experts' tacit knowledge into more comprehensible forms. Some tacit knowledge that comes from experts, specialists or customers, is not easy to understand. Many of these cases contain complex theories and jargon. Therefore, in order to make this knowledge usable, it must be translated into more comprehensible forms.

- $\quad$ Combination (Explicit knowledge $\rightarrow$ Explicit knowledge): Combination refers to the creation of new knowledge by reorganizing, consolidating, and synthesizing existing explicit knowledge into new complex yet usable forms of explicit knowledge (Nonaka, 1994; Alavi, 2001). In this stage, there are three significant processes involved with converting explicit knowledge into new explicit knowledge. The first process is gathering and integrating. This process is to gather and integrate the explicit knowledge from the Externalization stage into new explicit knowledge. The second process is transferring and disseminating. This process is to transfer and disseminate the new explicit knowledge in an organization. The third process is editing and processing. This process is to make the explicit knowledge become more usable. A good example is consolidating and synthesizing existing explicit knowledge into documents such as reports, plans, etc.

- Internalization (Explicit knowledge $\rightarrow$ Tacit knowledge): Internalization refers to creation of new knowledge by converting explicit knowledge in an organization into individual's tacit knowledge (Nonaka, 1994; Alavi, 2001). The processes in this stage that can enable individuals to internalize the knowledge are 
training, learning-by-doing, practice, exercises, etc. In this stage, there are two significant processes involved with converting explicit knowledge into individual's tacit knowledge. The first process is that the explicit knowledge must be embodied in an organization's action and practice. This is, for example, the training activity enabling individuals to internalize the knowledge. The second process is to conduct those processes in which explicit knowledge has been embodied.

\section{CUSTOMER RELATIONSHIP MANAGEMENT \& KNOWLEDGE MANAGEMENT}

In this section, we will focus on the relationship among customer relationship management, customer knowledge, knowledge management, and knowledge creation.

\section{CRM and Customer Knowledge}

Gebert et al. (2003) refer to the knowledge which flows in CRM processes as "Customer Knowledge," which can be categorized into three types of knowledge:

1) Knowledge for customers: This knowledge is used to respond to customers' knowledge needs. Examples of this knowledge are knowledge on products, markets, and suppliers.

2) Knowledge about customers: This knowledge is gathered for understanding customers' needs and motivations in order to provide them with personalized service. Examples of this knowledge are customers' histories, customers' requirement, etc.

3) Knowledge from customers: This knowledge is obtained through interactions with customers. Examples of this knowledge are customers' knowledge on products, markets and suppliers. This knowledge can be used for sustainable and continuous improvement.

The importance of customer knowledge in CRM is also recognized by Oracle. Oracle, which is one of the biggest software companies in the world, mentions that CRM "is about knowing your customers better and effectively using that knowledge to own their total experience with your business, and to drive revenue growth and profitability" (Stefanou \& Sarmaniotis, 2003, p. 618). Gebert et al. (2003) also recognize the importance of customer knowledge in CRM, stating that in CRM, customer knowledge on their needs, motivations, and behavior needs to be acquired and kept it up-to-date continuously. It is necessary to apply customer knowledge in CRM for continuous performance improvement.

Customer knowledge is important not only for CRM, but for the organization. According to an international survey conducted by Chase (1997), 82\% of total respondents viewed customer knowledge as extremely critical to organization success. A survey of European and North American companies by Skyrme and Amidon (1997) also suggests that customer knowledge is very important, since $96 \%$ of total respondents perceived customer knowledge as the most important asset for maintaining organization competitiveness (quoted in Bennet \& Gabriel, 1999). Therefore, the knowledge that is most valuable to a company is customer knowledge (Gebert et al., 2003).

\section{Customer Knowledge, CRM, and Knowledge Management}

In the previous section, the importance of customer knowledge in CRM has been specified. In this section, we will focus on the importance of knowledge management in CRM. Davenport et al. (2001) mention that, to construct good relationships with customers, customer knowledge must be managed in order to provide customized service for each individual. From what Davenport et al. (2001) have mentioned, we can refer that knowledge management can be used to manage customer knowledge in CRM. Romano (2000) also recognizes the importance of knowledge management in CRM, in that a company needs to explore and refine knowledge management in CRM in order to obtain more value-added knowledge and understand customers more in terms of purchasing patterns, attitudes and preferences.

The examples of knowledge management that improve CRM are: 1) knowledge management enables the Customer Communication Center of a Mutual Fund company to provide faster response to customers and better quality of service (Bueren et al., 2004), 2) In the case of a customer-oriented human resource management 
instrument at a health insurance company, knowledge management provides more robust processes and timeliness in its operation (Bueren et al., 2004), 3) In a case study from South Africa, knowledge management can assist CRM in terms of improving customer knowledge management which leads to better response to customers' needs (Plessis \& Boon, 2004).

Therefore, it can be concluded that knowledge management is significantly related to CRM, especially in terms of customer knowledge management (Romano, 2000; Stefanou \& Sarmaniotis, 2003; Plessis \& Boon, 2004; Bueren et al., 2004).

\section{Customer Knowledge, Knowledge Creation, and CRM}

Knowledge creation is one of the four basic knowledge processes which are: 1) knowledge creation, 2) knowledge storage/retrieval, 3) knowledge transfer, and 4) knowledge application (Alavi \& Leidner, 2001). In CRM, the knowledge creation process can improve a company in terms of better understanding of customers. This process also improves integration of customer knowledge into organization knowledge. Since the flow of knowledge in the knowledge creation process is in spiral movement (Nonaka, 1994; Nonaka, 1998), the customer knowledge not only becomes organization knowledge, it also internalizes into organizational members as well. Therefore, customer knowledge is engraved within both company and organizational members. In other words, it is the process of sustainably creating knowledge focusing on customer knowledge in an organization. Therefore, according to this concept, we develop a "Customer-Centric Knowledge Creation for Customer Relationship Management" framework.

\section{CUSTOMER-CENTRIC KNOWLEDGE CREATION FOR CUSTOMER RELATIONSHIP MANAGEMENT: THE CONCEPTUAL FRAMEWORK}

In this section, the conceptual framework of Customer-Centric Knowledge Creation for CRM implementation is proposed. This framework is developed from Nonaka (1998)'s SECI model in the perspective of Chen and Popovich (2003)'s customer relationship management implementation model. There are two reasons why this framework is developed based on these two models. First, for knowledge creation SECI model is widely accepted in the knowledge management field and is very practical in terms of identifying how knowledge can be created, and Nonaka Ikujiro is a renowned expert in terms of knowledge creation. Second, for CRM model, as mentioned, people, process, and technology have important roles for implementing CRM. Chen and Popovich (2003)'s CRM implementation model can identify and focus on these key dimensions when implementing CRM. It also identifies the context in which these dimensions should be developed, i.e. enterprise-wide, customer-centric, technology-driven, cross-functional organization.

In terms of developing this conceptual framework, we focus on the definitions and concepts of these two models. CRM combines three key dimensions which are people, process, and technology within the context of enterprise-wide, customer-centric, technology-driven, cross-functional organization (Chen \& Popovich, 2003). Knowledge creation is a process which involves the interactions between tacit and explicit knowledge that lead to the creation of knowledge. Nonaka (1998) had proposed the SECI model as a model for knowledge creation. SECI suggests the four basic stages of creating knowledge in an organization, which are socialization, externalization, combination, and internalization.

Therefore, Customer-Centric Knowledge Creation is a process which involves interactions between tacit knowledge and explicit knowledge that lead to the creation of knowledge based on customer knowledge within the context of enterprise-wide, customer-centric, technology-driven, cross-functional organization. The conceptual framework of Customer-Centric Knowledge Creation consists of four stages as shown in Figure 3. 


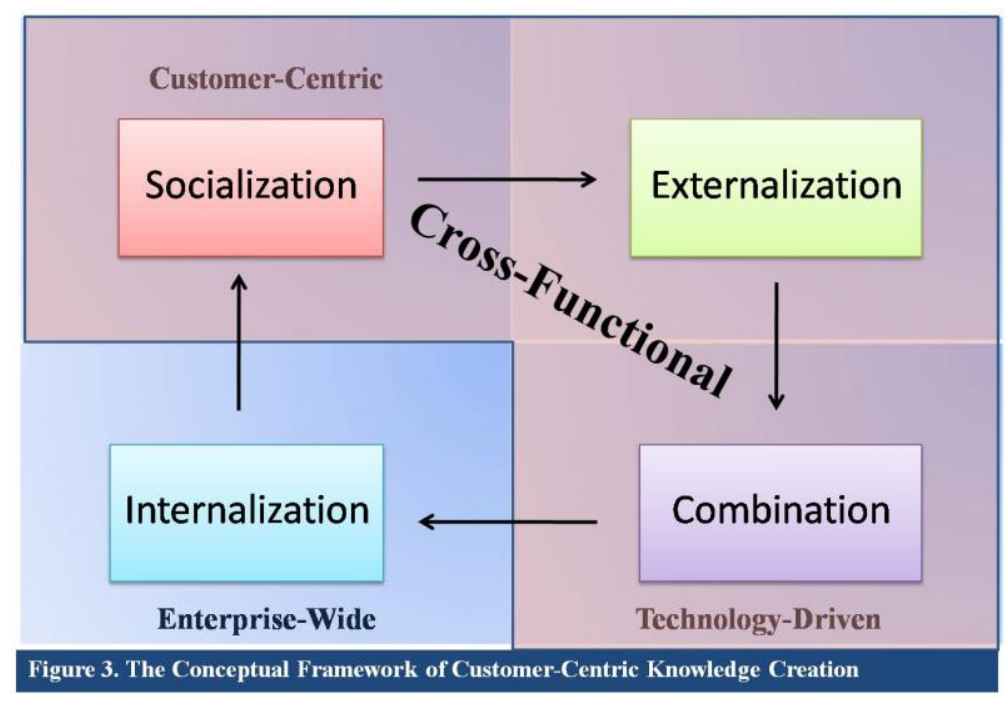

\section{Cross-Functional and Customer-Centric Socialization}

According to Nonaka (1998)'s SECI model, socialization refers to creation of new knowledge by exchanging individual's tacit knowledge with another individual's tacit knowledge through mutual activities (Nonaka, 1998; Alavi \& Leidner, 2001). As mentioned in the previous section, mutual activities refer to activities that bring individuals together to spend time in the same environment rather than following verbal or documented instructions. Cross-functional and customer-centric socialization refers to the creation of new knowledge by exchanging customers' tacit knowledge with tacit knowledge of cross-functional organizational members through mutual activities. In other words, it is socialization that is focusing on customer knowledge.

Cross-functional organizational members refer to forming a cross-functional team of people from various departments in an organization with different specific knowledge (e.g. salesperson, IT manager, production planner, marketing agent, etc.). The reason why the company should form this cross-functional team is based on tacit knowledge of organizational members. Since tacit knowledge is comprised of two dimensions, technical side (e.g. personal skill, expertise, know-how, etc.) and cognitive side (e.g. personal values, beliefs, ideals, etc.) (Nonaka, 1998), members in various departments will have different tacit knowledge, especially personal skill and expertise. For instance, a marketing agent usually has more marketing expertise than an IT specialist, who usually has more technological expertise. With these different skills and expertise, people can perceive a situation in different ways (since skill and expertise are the technical side of an individual's tacit knowledge). The benefit from forming a cross-functional team is elaborated more in the examples of cross-functional and customer-centric socialization.

As Nonaka (1995) mentions, in practice, direct interaction with customers supports the process of acquiring knowledge. Therefore, in cross-functional and customer-centric socialization, mutual activities which allow direct interaction between organizational members and customers must be conducted. The examples of activities in crossfunctional and customer-centric socialization can be categorized into two fields, which are:

- $\quad$ Business-to-Business: Conducting "Let's Understand Our Customer" trip. In this trip, the cross-functional team will go to the customer's company to participate in mutual activities with the organizational members of that company. This is not a company tour. The cross-functional team must see and participate in the customer company's activities. For instance, the cross-functional team from a machine manufacturer for canned goods should go to the customer's plant, to see and work together with organization members of the customer's company. This mutual activity allows interaction of tacit knowledge through shared experience. This approach will help the machine manufacturer to understand its customers better. The benefit of a cross-functional team is that, since each member has different expertise, they can understand the customer from a wider perspective, which includes their needs, cultures, motivation, etc. For example, if only marketing agents are involved, the acquired knowledge is likely to be from a marketing perspective (e.g. 
motivation to buy) since it is their area of expertise. However, if an IT specialist is in the team, the acquired knowledge is likely to be gained more from an IT perspective (e.g. need for new functions in a machine).

- Business-to-Consumer: Conducting "Let's Get Together Day" event. Companies should conduct an event that allows organizational members of a cross-functional team to meet with their customers. This event is not just a meeting, as there must be mutual activities that allow direct interactions between organizational members and customers. For instance, a fashion brand conducts a "Let's Get Together Day" event that allows its customers to participate. In this event, customers will meet with organizational members of a cross-functional team (e.g. designers, cutting specialists, etc.) and participate in activities together (helping each other to design T-shirts, helping each other to make a hat, etc.).

The benefit of cross-functional and customer-centric socialization is that the organization is able to obtain customer knowledge, gain more comprehension of their customers and learn their experiences. At the same time, the customers are able to gain more understanding of the organization from direct interaction with organizational members.

\section{Cross-Functional Externalization}

According to Nonaka (1998)'s SECI model, externalization refers to creation of new knowledge by expressing individual's tacit knowledge and translating it into new comprehensive explicit knowledge that can be understood by others (Nonaka, 1998; Alavi, 2001). As dialogue is the key to converting tacit knowledge into explicit knowledge (Nonaka, 1998), cross-functional externalization refers to the creation of new knowledge by expressing tacit knowledge of organizational members through dialogue in a cross-functional team, translating it into new comprehensive explicit knowledge. In other words, it is externalization that is conducted through cross-functional dialogue.

In the previous stage, organizational members in a cross-functional team have obtained customer knowledge and it becomes his/her own tacit knowledge. In this stage, that tacit knowledge must be converted into explicit form which is more easily understood by other organizational members. In other words, it is converting his/her tacit knowledge from a previous stage into words, charts, images, models, speeches, visuals, etc. However, the process of converting tacit knowledge into explicit knowledge is not easy. Therefore, there must be some approaches to assist organizational members to articulate that tacit knowledge.

The approach which is used in this stage is called "Cross-Functional Dialogue." Cross-functional dialogue refers to the activity that assists an organizational member in articulating his/her tacit knowledge through dialogue in a cross-functional team. The reason why dialogue should be conducted in a cross-functional team is that, as mentioned, since skill and expertise are a part of tacit knowledge, people with different expertise can perceive the same situation from different perspectives. These different perspectives have benefits in assisting the articulation and translation process of tacit knowledge. Through dialogue, people with different perspectives can stimulate another organizational member to consider from a perspective that is different from his/her own. This assists in articulating his/her tacit knowledge. This dialogue does not just assist another member to articulate the tacit knowledge, it also reflects to other members to think about and analyze themselves.

The benefit of conducting cross-functional externalization is that customer knowledge from the previous stage which becomes a part of members' tacit knowledge, can be articulated and translated into a more comprehensive form which is more convenient for further use. Members in cross-functional teams can also reflect on and analyze themselves too.

\section{Cross-Functional and Technology-Driven Combination}

According to Nonaka (1998)'s SECI model, combination refers to creation of new knowledge by reorganizing, consolidating, and synthesizing existing explicit knowledge into new complex yet usable forms of explicit knowledge (Nonaka, 1994; Alavi, 2001). Cross-functional and technology-driven combination refers to the creation of new knowledge by reorganizing, consolidating, and synthesizing existing explicit knowledge from crossfunctional departments into new complex yet usable forms of explicit knowledge within the context of technology as 
a driver or enabler to assist the creation of knowledge. In other words, it is combination with a cross-functional and technology-driven perspective.

In the previous stage, the tacit knowledge (that includes the customer knowledge) of organizational members has been converted into explicit knowledge. The form of explicit knowledge created in the previous stage can vary from hardcopy (e.g. presentations, documents, charts, etc.) to softcopy (e.g. Word document file, image file, etc.). Since these forms of explicit knowledge reside within many departments or are scattered in crossfunctional working units, they need to be managed, organized and synthesized.

In this stage, those various forms of explicit knowledge existing in each department and cross-functional team are gathered, managed, organized and synthesized. Technology has a role in this process. It is a driver or enabler to facilitate the knowledge creation in this stage. Hardcopy forms of knowledge can be converted to softcopy forms using various kinds of technology (e.g. scanners, optical character recognition, etc.). Some technology is able to assist in capturing and managing the knowledge (e.g. file management system, database, data warehouse, intranet, etc.). These forms of explicit knowledge can be consolidated and synthesized in order to create more usable, standardized, and comprehensive knowledge. This leads to the transformation of the new knowledge, in which customer knowledge (from the previous two stages) is embedded, into organizational knowledge.

The benefit from conducting cross-functional and technology-driven combination is to make all forms of explicit knowledge scattered throughout many parts of an organization become more organized, usable, standardized, and understandable. The accessibility of the new knowledge also increases since it is stored and organized systematically with the aid of software and other technology. This stage also assists in converting the customer knowledge into organization knowledge. As mentioned earlier, the technology is the enabler and driver for facilitating the change in business process and improving organization performance. Therefore, the selected software and technology should be necessary and relevant rather than complex and sophisticated. It is not mandatory to implement a new system or new technology, but depends on the efficiency of the current system or technology and whether, or how well, it can answer or respond to the organization's need.

\section{Enterprise-Wide Internalization}

According to Nonaka (1998)'s SECI model, internalization refers to creation of new knowledge by converting explicit knowledge in an organization into individual's tacit knowledge (Nonaka, 1994; Alavi, 2001). Enterprise-wide internalization refers to the creation of new knowledge by converting explicit knowledge throughout an organization into the tacit knowledge of organizational members. In other words, it is internalization that is conducted from an enterprise-wide perspective. This means the Internalization process is not focused only in some parts of the organization but conducted throughout the organization.

In the previous stage, the explicit knowledge (in which customer knowledge is embedded) has been standardized, made usable and more comprehensive, and become organization knowledge. In this stage, through the learning-by-doing activities, training and exercises, organization members are able to internalize the organization knowledge. In other words, they begin to use the organization knowledge to extend and restructure their own tacit knowledge. Since, at this stage, the customer knowledge has become a part of organization knowledge, organizational members also internalize the customer knowledge as well. This leads to creating a customer-focused mindset to organizational members.

The benefit from conducting enterprise-wide internalization is to make the organization knowledge become a part of organizational members and create a customer-focused mindset in organizational members. When the mindset of organizational members has the same direction, it will drive the organization towards its goal more efficiently.

\section{CONCLUSION}

Customer knowledge plays an important role, not only in the organization (Chase, 1997; Bennet \& Gabriel, 1999; Gebert et al., 2003) but in customer relationship management (CRM) (Stefanou \& Sarmaniotis, 2003; Gebert 
et al., 2003) as well. CRM can assist firms to know their customers better and develop good relationships with them. However, in order to achieve these two objectives of CRM, the firms should focus on customer knowledge (Stefanou \& Sarmaniotis, 2003; Gebert et al., 2003; Bueren et al., 2004). Customer knowledge must be acquired in order to get to know customer needs and motivation (Stefanou \& Sarmaniotis, 2003; Gebert et al., 2003). Customer knowledge must also be managed in order to build good relationships with customers (Davenport et al., 2001). Knowledge management, including knowledge creation, can assist in terms of acquiring and managing customer knowledge. Knowledge creation allows the enhancement of knowledge through dynamic interaction of knowledge and creates new knowledge in the organization continuously (Nonaka, 1994; Rice \& Rice, 2008). The benefit of knowledge management in CRM is that it can assist the companies to gain more understanding of their customers (Romano, 2000). It also assists in improving business process performance and quality of service in responding to customer needs (Plessis \& Boon, 2004; Bueren et al., 2004).

Customer-Centric Knowledge Creation is the process for the creation of knowledge based on customer knowledge within the CRM contexts, which are enterprise-wide, customer-centric, technology-driven, and crossfunctional. The benefit of this process is that it assists organizations by gaining more understanding of customers, embedding customer knowledge into organization knowledge, and creating a customer-focused mindset in organizational members. It is the process of sustainably creating knowledge focusing on customer knowledge in an organization. This framework can also be used to analyze knowledge creation in CRM implementation. For further research, the topic can focus on the extension of this concept to other processes in knowledge management, which are knowledge storage/retrieval, knowledge transfer, and knowledge application in the CRM context. Additionally, the topic of obstacles that hinder the Customer-Centric Knowledge Creation process is interesting for further study.

\section{AUTHOR INFORMATION}

Phocharapol Srisamran is a doctoral student at the College of Management, Mahidol University, Thailand. He received his Bachelor of Science degree in Information Technology from Sirindhorn International Institute of Technology, Thammasat University, Thailand and Master of Management from the College of Management, Mahidol University. His research interests include knowledge management and customer relationship management. E-mail: cmtopphoch@gmail.com (Corresponding author)

Vichita Vathanophas Ractham, Ph.D., is currently an Assistant Professor in the College of Management, Mahidol University, Thailand and teaches knowledge management, management information system, and consulting practice in the Master of Management, International Program. Previously she taught for two years in the School of Computing, Department of Information System, National University of Singapore (NUS), in the same areas. She received her B.Sc. (1992) in Business Administration (concentration: Statistics) from Chulalongkorn University, Thailand and M.Sc. (1995) and Ph.D. (2000) in Information Science from the University of Pittsburgh, USA. Her primary research interests include knowledge management, social interaction in teamwork, enterprise resource planning, and e-learning. E-mail: vichita.rac@ mahidol.ac.th

\section{REFERENCES}

1. Alavi, M., \& Leidner, D. E. (2001). Review: Knowledge management and knowledge management systems: Conceptual foundations and research issues. MIS quarterly, 107-136.

2. Andreeva, T., \& Ikhilchik, I. (2011). Applicability of the SECI model of knowledge creation in Russian cultural context: Theoretical analysis. Knowledge and Process Management, 18(1), 56-66.

3. Bennett, R., \& Gabriel, H. (1999). Organisational factors and knowledge management within large marketing departments: An empirical study. Journal of Knowledge Management, 3(3), 212-225.

4. Bentum, R. V., \& Stone, M. (2005). Customer relationship management and the impact of corporate culture A European study. The Journal of Database Marketing \& Customer Strategy Management, 13(1), 28-54.

5. Bose, R. (2002). Customer relationship management: Key components for IT success. Industrial Management \& Data Systems, 102(2), 89-97.

6. Bueren, A., Schierholz, R., Kolbe, L., \& Brenner, W. (2004, January). Customer knowledge managementimproving performance of customer relationship management with knowledge management. In System Sciences, 2004. Proceedings of the 37th Annual Hawaii International Conference on (pp. 10-pp). IEEE. 
7. Chase, R. L. (1997). The knowledge-based organization: An international survey. Journal of Knowledge Management, 1(1), 38-49.

8. Chen, I. J., \& Popovich, K. (2003). Understanding customer relationship management (CRM): People, process and technology. Business Process Management Journal, 9(5), 672-688.

9. Davenport, T. H., Harris, J. G., \& Kohli, A. K. (2001). How do they know their customers so well? MIT Sloan Management Review, 42(2), 63-73.

10. Davenport, T. H., \& Prusak, L. (1998). Working knowledge: Managing what your organization knows. Boston, MA: Harvard Business School Press.

11. Gebert, H., Geib, M., Kolbe, L., \& Brenner, W. (2003). Knowledge-enabled customer relationship management: Integrating customer relationship management and knowledge management concepts [1]. Journal of Knowledge Management, 7(5), 107-123.

12. Grant, R. M. (1996). Toward a knowledge-based theory of the firm. Strategic Management Journal, 17, 109-122.

13. Gupta, A. K., \& Govindarajan, V. (2000). Knowledge flows within multinational corporations. Strategic Management Journal, 21(4), 473-496.

14. Kimberly, J. R., \& Evanisko, M. J. (1981). Organizational innovation: The influence of individual, organizational, and contextual factors on hospital adoption of technological and administrative innovations. Academy of Management Journal, 24(4), 689-713.

15. Meyer, A. D., \& Goes, J. B. (1988). Organizational assimilation of innovations: A multilevel contextual analysis. Academy of Management Journal, 31(4), 897-923.

16. Nonaka, I., \& Konno, N. (1998). The concept of "Ba": Building a foundation for knowledge creation. California Management Review, 40(3), 40-54.

17. Nonaka, I., \& Takeuchi, H. (1995). The knowledge-creating company: How Japanese companies create the dynamics of innovation. New York: Oxford University Press.

18. Nonaka, I. (1994). A dynamic theory of organizational knowledge creation. Organization Science, 5(1), 1437.

19. Paas, L., \& Kuijlen, T. (2001). Towards a general definition of customer relationship management. Journal of Database Marketing, 9(1), 51-60.

20. Parvatiyar, A., \& Sheth, J. N. (2001). Customer relationship management: Emerging practice, process, and discipline. Journal of Economic and Social Research, 3(2), 1-34.

21. Payne, A., \& Frow, P. (2005). A strategic framework for customer relationship management. Journal of Marketing, 167-176.

22. Plessis, M. D., \& Boon, J. A. (2004). Knowledge management in eBusiness and customer relationship management: South African case study findings. International Journal of Information Management, 24(1), 73-86.

23. Prasongsukarn, K. (2009). Customer relationship management: From theory to practice. AU-GSB $e$ Journal, 2(1), 17-32.

24. Rice, J. L., \& Rice, B. S. (2005). The applicability of the SECI model to multi-organisational endeavours: an integrative review. International Journal of Organisational Behaviour, 9(8), 671-682.

25. Romano Jr., N. C. (2000). Customer relations management in information systems research. AMCIS 2000 Proceedings. Paper 17.

26. Stefanou, C. J., Sarmaniotis, C., \& Stafyla, A. (2003). CRM and customer-centric knowledge management: An empirical research. Business Process Management Journal, 9(5), 617-634.

27. Stein, E. W., \& Zwass, V. (1995). Actualizing organizational memory with information systems. Information Systems Research, 6(2), 85-117.

28. Walsh, J. P., \& Ungson, G. R. (1991). Organizational memory. Academy of Management Review, 16(1), 57-91. 